\title{
Ocular complaints from students during COVID-19 pandemic
}

\author{
Ada Sterczewskaa ${ }^{1, A, B, D}$, Alicja Wojtyniak ${ }^{1, C, D}$, Ewa Mrukwa-Kominek ${ }^{2, E, F}$ \\ ${ }^{1}$ Students' Scientific Society, Department of Ophthalmology, Faculty of Medical Sciences in Katowice, Medical University of Silesia in Katowice, Poland \\ ${ }^{2}$ Department of Ophthalmology, Faculty of Medical Sciences in Katowice, Medical University of Silesia in Katowice, Poland \\ A - research concept and design; $\mathrm{B}$ - collection and/or assembly of data; $\mathrm{C}$ - data analysis and interpretation; \\ $D$ - writing the article; $E$ - critical revision of the article; $F$ - final approval of the article
}

\section{Address for correspondence \\ Ada Sterczewska}

E-mail: adasterczewska@gmail.com

Funding sources

None declared

Conflict of interest

None declared

Acknowledgements

We would like to thank Prof. Dorota Pojda-Wilczek, tutor of Students' Scientific Society, for her comments which helped to improve the manuscript.

Received on August 17, 2021

Reviewed on September 13, 2021

Accepted on November 23, 2021

Published online on January 25, 2022

\section{Abstract}

Background. During coronavirus disease 2019 (COVID-19) pandemic, students were obliged to switch to online learning. Nevertheless, a long time spent in front of the screens is one of the risk factors of dry eye disease (DED).

Objectives. To evaluate ocular symptoms typical for DED presented by Polish students during online learning and entertainment before and during the pandemic, as well as to assess the prevalence of these symptoms.

Materials and methods. The original questionnaire was distributed online via social media (Facebook) to Polish students in November 2020. Three hundred sixty-eight anonymous questionnaires were collected and statistically analyzed.

Results. During the pandemic, online learning and screen entertainment time extended on average by $4 \mathrm{~h}$ and 40 min, respectively. Only $8 \%$ of students admitted to having no ocular symptoms and 77\% reported the exacerbation in previous ocular complaints. Reported symptoms included pain/discomfort of the eyes, itchiness, dryness, red eyes, feeling gritty particles under eyelids, and blurred vision. Actions such as using eye drops, having breaks from studying to have distant vision, consultation with an ophthalmologist, using warm and cold compresses, or none of these were undertaken by $45 \%, 42 \%, 8 \%, 7 \%$, and $19 \%$ of students, respectively. Nonmedical students reported worsening of previous symptoms more often than medical students $(p<0.05)$. A correlation was observed between the number of new/intensified symptoms and the change in screen learning time $(r=0.17, p<0.05)$.

Conclusions. Eye complaints are prevalent in the population of students. During the pandemic these symptoms intensified, which may have been caused by the extension of the screen time. There is a need for better education on ocular hygiene to improve visual clarity and awareness of risk factors of DED.

Key words: students, online learning, dry eye disease, COVID-19, eye complaints

Cite as

Sterczewska A, Wojtyniak A, Mrukwa-Kominek E. Ocular

complaints from students during COVID-19 pandemic.

Adv Clin Exp Med. 2022;31(2):197-202.

doi:10.17219/acem/144199

DOI

10.17219/acem/144199

Copyright

Copyright by Author(s)

This is an article distributed under the terms of the

Creative Commons Attribution 3.0 Unported (CC BY 3.0)

(https://creativecommons.org/licenses/by/3.0/) 


\section{Background}

The coronavirus disease 2019 (COVID-19) pandemic began in December 2019 in China and changed everyone's life, including students. During the pandemic, Polish students were obliged to switch to online learning from March 2020. ${ }^{1}$ Nevertheless, a long time spent in front of the screens is one of the well-known risk factors of the dry eye disease (DED). ${ }^{2}$ Dry eye disease is a complex, multifactorial condition of the ocular surface where the loss of homeostasis and hyperosmolarity, as well as the instability of the tear film are observed. ${ }^{3}$ Worldwide, this is the most common ocular disease and it is becoming more frequent along with the aging society, increasing prevalence of using digital devices and the development of a more stressful social environment. ${ }^{4-7}$ What is more, DED has an influence on the quality of life and vision, and decreases productivity at work. ${ }^{8-9}$ The influence of COVID-19 pandemic is much broader; its impact on psychological well-being was observed as the increase in anxiety prevalence in the general population, as well as in the specific communities such as healthcare professionals and medical students. ${ }^{10-13}$ During a break in traditional medical training, the latter group experienced the augmented risk of mental or psychological symptoms, such as depression and suicidal ideations, as compared to general population. It can be assessed as a negative effect of COVID-19 on education, especially severe in the group of respondents in our study. ${ }^{14}$

\section{Objectives}

Our aim was to evaluate ocular symptoms typical for DED presented by Polish students during online learning and entertainment before and during the pandemic, as well as to assess the prevalence of these symptoms.

\section{Materials and methods}

At the beginning of the study, the interviews regarding e-learning and changes in ocular complaints during the pandemic were conducted with 20 students in October 2020. The original online questionnaire based on those students' suggestions, DED symptoms and our own ideas was prepared and distributed to Polish students in November $2020 .^{3}$ The survey was created using Google Forms and consisted of 24 questions (17 single-choice, 3 multiple-choice and 4 open questions). The questions concerned mainly basic demographic data, the field of study, DED symptoms before (while attending classes at a university) and during COVID-19 pandemic (from March to November 2020), the change in screen time spent on learning and leisure activities, and actions undertaken because of the symptoms. The survey was posted online on students' Facebook groups with a short invitation to complete it. The data collection was carried out in November 2020. A total of 377 questionnaires were obtained and 9 of them were excluded due to being incomplete or incorrect. The data was collected and analyzed anonymously.

\section{Statistical analyses}

Statistical analyses included descriptive methods as well as the association and significance of different methods. The $\chi^{2}$ tests were performed for the categorical data. When the class size was less than 5, the Fisher's exact test was used. For quantitative data, the Shapiro-Wilk test was used to assess data distribution normality. We applied MannWhitney U test in order to compare the differences among the groups as the number of new/intensified symptoms, age (years), the change in screen learning time (h) and the change in screen entertainment time (h) were found to be non-normally distributed (more details available in Table 5). Spearman's rank correlation was calculated to compare the number of new/intensified symptoms with the change in screen learning time. A p-value $<0.05$ was considered statistically significant.

\section{Results}

Data were collected from 368 students, out of which $82 \%$ were female. Mean age was 23 years ( $95 \%$ confidence interval (95\% CI): [22.7; 23.27]). The median duration of studying was 4 years. Fifty-six percent of the participants were medicine students, others chose nonmedical courses of study. The largest group of respondents were students of the Medical University of Silesia, Katowice, Poland (40\%).

An autoimmune disease was reported by $7 \%$ of respondents. Seven percent of students were active smokers. As many as $41 \%$ wore glasses every day, 22\% wore glasses occasionally and $37 \%$ did not wear glasses at all. About $8 \%$ of students declared everyday use and $14 \%$ declared occasional use of contact lenses. There were $34 \%$ of students under the ophthalmologist's care before the time of pandemic, out of which $82 \%$ were under the ophthalmologist's care due to the refractive error. One interviewee's cause was DED. Other diagnoses included strabismus, lymphangioma, demodicosis, nystagmus, and suspicion of glaucoma.

The online learning time during the pandemic, in comparison to the period before the pandemic, extended according to $94 \%$, remained the same according to $5 \%$ and shortened according to $1 \%$ of respondents. On average, online learning time extended by $4 \mathrm{~h}(95 \% \mathrm{CI}$ : [3.86; 4.15]). A correlation was observed between the number of new/intensified symptoms and the change in screen learning time $(\mathrm{r}=0.1750, \mathrm{p}<0.05$, degrees of freedom $(\mathrm{df})=285$, Spearman's rank correlation). A prolonged screen entertainment time was reported by $47 \%$ of students, no change by $37 \%$ and $16 \%$ of students decided 
Table 1. The ocular symptoms that appeared for the first time during coronavirus disease 2019 (COVID-19) pandemic

\begin{tabular}{|c|c|c|c|}
\hline New symptoms during COVID-19 & Number of students & $\begin{array}{l}\% \text { of all students } \\
\qquad(n=368)\end{array}$ & $\begin{array}{l}\% \text { of students with new } \\
\text { symptoms }(n=132)\end{array}$ \\
\hline Itchiness & 61 & 17 & 46 \\
\hline Pain/discomfort of the eyes & 71 & 19 & 54 \\
\hline Dryness of the eyes & 55 & 15 & 42 \\
\hline Feeling gritty particles under eyelids & 35 & 10 & 27 \\
\hline Red eyes & 43 & 12 & 33 \\
\hline Discharge & 5 & 1 & 4 \\
\hline Other & 6 & 2 & 5 \\
\hline
\end{tabular}

Table 2. The ocular symptoms that intensified during coronavirus disease 2019 (COVID-19) pandemic

\begin{tabular}{|l|c|c|c|}
\multicolumn{1}{|c|}{$\begin{array}{c}\text { More severe symptoms during COVID-19 } \\
\text { pandemic }\end{array}$} & Number of students & \% of all students $(n=368)$ & $\begin{array}{c}\text { \% of students with more } \\
\text { severe symptoms ( } n=282)\end{array}$ \\
\hline Itchiness & 169 & 46 & 60 \\
\hline Pain/discomfort of the eyes & 179 & 49 & 63 \\
\hline Dryness of the eyes & 187 & 51 & 66 \\
\hline Feeling gritty particles under eyelids & 54 & 15 & 19 \\
\hline Red eyes & 116 & 32 & 41 \\
\hline Discharge & 20 & 5 & 7 \\
\hline Other & 7 & 2 & 2 \\
\hline
\end{tabular}

to cut down the entertainment time. It was extended by about $40 \mathrm{~min} / 0.6 \mathrm{~h}$ on average $(95 \% \mathrm{CI}:[0.44 ; 0.76])$.

Reported symptoms included pain/discomfort of the eyes, itchiness, dryness of the eyes, red eyes, feeling gritty particles under eyelids, and blurred vision. A detailed distribution of new symptoms is demonstrated in Table 1 and the distribution of the symptoms that intensified during COVID-19 is shown in Table 2. The mean number of the new/intensified symptoms was 3 .

A deterioration of visual acuity during COVID-19 pandemic was declared by $41 \%$ of participants, $44 \%$ of whom noticed the improvement after blinking a few times. About $21 \%$ of interviewees were uncertain about their vision and 39\% denied any problems with vision acuity. Actions such as using eye drops, having breaks from studying to have distant vision, consultation with an ophthalmologist, using warm and cold compresses on eyes, or none of these were undertaken by $45 \%, 42 \%, 8 \%, 7 \%$, and $19 \%$ of students, respectively.

Only $3 \%$ of students complained about ocular symptoms for the first time during COVID-19 pandemic. Twelve percent of participants stated that their symptoms started before the pandemic and did not change. More symptoms or increased severity of symptoms were observed in $77 \%$ of cases. Only $8 \%$ of respondents claimed to have no ocular problems. Therefore, we decided to compare students with no change (NC) in symptoms (asymptomatic/with the same intensity in symptoms) with those who experienced more symptoms or their symptoms became more severe during the pandemic - change group (C). Online learning time increased in the change group to a greater extent $\left(\mathrm{p}=0.0003, \mathrm{df}=2, \mathrm{X}^{2}=16.25\right)$, although the group was more eager to decrease the time spent on online entertainment compared to those unaffected $(\mathrm{p}=0.0016$, $\left.\mathrm{df}=2, \mathrm{X}^{2}=12.84\right)$. Moreover, they experienced decreased visual acuity more often than the other group (C: $45 \%$, NC: $\left.20 \% ; p<0.0001, \chi^{2}=18.53\right)$. Students from the change group used eye drops more frequently (C: 48\%, NC: 16\%; $\left.\mathrm{p}<0.0001, \mathrm{df}=1, \mathrm{X}^{2}=24.88\right)$, and more of them took breaks from studying to look into the distance (C: $47 \%$, NC: $17 \%$; $\left.\mathrm{p}<0.0001, \mathrm{df}=1, \mathrm{X}^{2}=21.87\right)$. A more detailed analysis of the results is presented in Table 3 .

Nonmedical students $(\mathrm{N})$ reported worsening of the previous symptoms more often than medical students (M) $\left(\mathrm{N}: 89 \%, \mathrm{M}: 72 \% ; \mathrm{p}<0.0001, \mathrm{df}=1, \mathrm{X}^{2}=17.01\right)$. The use of eye drops in symptomatic participants was similar in both groups (N: 39\%, M: 43\%; $\mathrm{p}=0.3369, \mathrm{df}=1$, $\left.X^{2}=0.92\right)$, as well as consulting the ophthalmologist $(\mathrm{N}: 6 \%$, M: $9 \% ; \mathrm{p}=0.1977, \mathrm{df}=1, \mathrm{X}^{2}=1.66$ ). Twenty-two percent of participants from nonmedical fields and $18 \%$ of those from the medical field denied taking any actions because of their symptoms ( $\mathrm{p}=0.2844, \mathrm{df}=1, \mathrm{X}^{2}=1.15$ ). Taking regular breaks from studying was declared by $48 \%$ of nonmedical students compared to $36 \%$ of medical students ( $\left.\mathrm{p}=0.0195, \mathrm{df}=1, \mathrm{X}^{2}=5.46\right)$. The comparison of medical and nonmedical students is presented in Table 4.

\section{Discussion}

To our knowledge, this is the first research on the symptoms of DED in Polish students during COVID-19 pandemic. Nevertheless, the recent studies on the influence 
Table 3. The comparison of students who experienced no change in their ocular symptoms and those who reported more symptoms or more severe symptoms than before the coronavirus disease 2019 (COVID-19) pandemic

\begin{tabular}{|c|c|c|c|c|c|c|c|c|}
\hline \multicolumn{2}{|c|}{ Category } & $\begin{array}{c}\text { Students with no } \\
\text { change in symptoms } \\
\text { (no change group }(n=75) \text { ) }\end{array}$ & $\%$ & $\begin{array}{c}\text { Students with more } \\
\text { severe/more symptoms } \\
\text { (change group }(n=293))\end{array}$ & $\%$ & Test value & df & $p$-value \\
\hline \multicolumn{2}{|l|}{ Female } & 47 & 63 & 255 & 87 & \multirow{2}{*}{$24.08^{a}$} & \multirow{2}{*}{1} & \multirow{2}{*}{$<0.0001$} \\
\hline \multicolumn{2}{|l|}{ Male } & 28 & 37 & 38 & 13 & & & \\
\hline \multicolumn{2}{|l|}{ Age } & $23 \pm 3$ years & - & $23 \pm 1.5$ years & - & $8947.00^{b}$ & N/A & 0.0012 \\
\hline \multicolumn{2}{|c|}{ Medical students } & 58 & 77 & 149 & 51 & \multirow{2}{*}{$17.01^{\mathrm{a}}$} & \multirow{2}{*}{1} & \multirow{2}{*}{$<0.0001$} \\
\hline \multicolumn{2}{|c|}{ Nonmedical students } & 17 & 23 & 144 & 49 & & & \\
\hline \multirow{3}{*}{ Spectacles } & everyday & 26 & 35 & 124 & 42 & \multirow{3}{*}{$1.57^{\mathrm{a}}$} & \multirow{3}{*}{2} & \multirow{3}{*}{0.4570} \\
\hline & sometimes & 17 & 23 & 63 & 22 & & & \\
\hline & no & 32 & 43 & 106 & 36 & & & \\
\hline \multirow{3}{*}{ Contact lenses } & everyday & 5 & 7 & 24 & 8 & \multirow{3}{*}{$0.27^{\mathrm{a}}$} & \multirow{3}{*}{2} & \multirow{3}{*}{0.8749} \\
\hline & sometimes & 10 & 13 & 42 & 14 & & & \\
\hline & no & 60 & 80 & 227 & 77 & & & \\
\hline \multicolumn{2}{|c|}{ Currently smoking } & 7 & 9 & 20 & 7 & $0.55^{\mathrm{a}}$ & 1 & 0.4574 \\
\hline \multicolumn{2}{|c|}{ Autoimmunologic diseases } & 4 & 5 & 22 & 7.5 & $-^{c}$ & 1 & 0.6211 \\
\hline \multicolumn{2}{|c|}{$\begin{array}{l}\text { Medications which can cause } \\
\text { DED }\end{array}$} & 27 & 36 & 101 & 34 & $0.39^{\mathrm{a}}$ & 2 & 0.8210 \\
\hline \multirow{3}{*}{$\begin{array}{l}\text { Time spent } \\
\text { on online } \\
\text { learning }\end{array}$} & increased & 64 & 85 & 281 & 96 & \multirow{3}{*}{$16.25^{\mathrm{a}}$} & \multirow{3}{*}{2} & \multirow{3}{*}{0.0003} \\
\hline & no changes & 11 & 15 & 9 & 3 & & & \\
\hline & decreased & 0 & 0 & 3 & 1 & & & \\
\hline \multirow{3}{*}{$\begin{array}{l}\text { Time spent } \\
\text { on online } \\
\text { entertainment }\end{array}$} & increased & 41 & 55 & 131 & 45 & \multirow{3}{*}{$12.84^{\mathrm{a}}$} & \multirow{3}{*}{2} & \multirow{3}{*}{0.0016} \\
\hline & no changes & 32 & 43 & 104 & 35 & & & \\
\hline & decreased & 2 & 3 & 58 & 20 & & & \\
\hline \multicolumn{2}{|c|}{ Under ophthalmologist's care } & 20 & 27 & 107 & 37 & $2.56^{a}$ & 1 & 0.1093 \\
\hline Decreased visio & cuity & 15 & 20 & 133 & 45 & $18.53^{\mathrm{a}}$ & 2 & $<0.0001$ \\
\hline Breaks & & 13 & 17 & 138 & 47 & $21.87^{a}$ & 1 & $<0.0001$ \\
\hline Eye drops & & 12 & 16 & 140 & 48 & $24.88^{a}$ & 1 & $<0.0001$ \\
\hline No actions & & 19 & 25 & 54 & 18 & $1.79^{\mathrm{a}}$ & 1 & 0.1810 \\
\hline
\end{tabular}

Tests used: ${ }^{a} X^{2}$ test; ${ }^{b}$ Mann-Whitney $U$ test; ${ }^{c}$ Fisher's exact test; DED - dry eye disease; $d f$ - degrees of freedom. Bold indicates statistically significant results $(p<0.05)$.

of increased time in front of a visual display terminal (VDT) on the ocular complaints from students during pandemic - Giannaccare et al. ${ }^{15}$ and Cartes et al. ${ }^{16}$ - showed many similarities to our observations. The high prevalence of DED symptoms in students, as well as a considerably extended time in front of a VDT during pandemic correlated with the deterioration of symptoms. Moreover, previous studies involving VDT users before the pandemic, pointed the same risk factors of DED, that being female sex and increasing age, similarly to our research. ${ }^{17,18}$ Furthermore, the prevalence of ocular symptoms related to DED was higher in our study (92\%) in comparison to the paper of Stapleton et al. $(5-50 \%) .{ }^{19}$ In our opinion, the small number of students who decided to consult their symptoms with an ophthalmologist (8\%) could be justified by a low awareness, a more difficult access to healthcare during COVID-19 pandemic, the self-medication, a bearable intensification of symptoms, or all of the above. We understand that it is the first comparison of ocular symptoms in students of medical and nonmedical courses. Medical students should supposedly be better educated on visual hygiene as well as symptoms and treatment of DED. Nonetheless, knowledge alone is sometimes not enough. It is thought-provoking that nonmedical students decided to reduce their time of online entertainment more often compared to their counterparts studying medicine. We have observed that conducting more and more activities and events such as courses, conferences, meetings, or sport classes online, could potentially intensify ocular symptoms globally. Therefore, there is a need for better education on ocular hygiene, breaks at work for improving visual clarity and awareness campaigns about risk factors of DED. ${ }^{17}$ The ocular complaints reported by students involved in e-learning should have prompted them to monitor their time spent in front of the electronic devices, and take proper actions in case of presenting any symptoms.

Considering the rapid growth of use of electronic devices all around the world, there is a need for further research 
Table 4. Comparison of medical and nonmedical students

\begin{tabular}{|c|c|c|c|c|c|c|c|c|}
\hline \multicolumn{2}{|c|}{ Category } & $\begin{array}{l}\text { Medical } \\
\text { students } \\
(n=207)\end{array}$ & $\begin{array}{c}\% \\
\text { of medical } \\
\text { students }\end{array}$ & $\begin{array}{l}\text { Nonmedical } \\
\text { students } \\
(n=161)\end{array}$ & $\begin{array}{l}\% \text { of nonmedical } \\
\text { students }\end{array}$ & $p$-value & Test value & df \\
\hline \multicolumn{2}{|l|}{ Female } & 152 & 73 & 150 & 93 & \multirow{2}{*}{$<0.0001$} & \multirow{2}{*}{$23.97^{\mathrm{a}}$} & \multirow{2}{*}{1} \\
\hline \multicolumn{2}{|l|}{ Male } & 55 & 27 & 11 & 7 & & & \\
\hline \multicolumn{2}{|l|}{ Age } & $23 \pm 1.5$ years & - & $22 \pm 3.75$ years & - & $<0.0001$ & $9165.00^{b}$ & $\mathrm{~N} / \mathrm{A}$ \\
\hline \multicolumn{2}{|c|}{ Change in ocular symptoms } & 149 & 72 & 144 & 89 & \multirow{2}{*}{$<0.0001$} & \multirow{2}{*}{$17.01^{\mathrm{a}}$} & \multirow{2}{*}{1} \\
\hline \multicolumn{2}{|c|}{ No change in symptoms } & 58 & 28 & 17 & 11 & & & \\
\hline \multirow{3}{*}{ Spectacles } & everyday & 85 & 41 & 65 & 40 & \multirow{3}{*}{0.9328} & \multirow{3}{*}{$0.1391^{\mathrm{a}}$} & \multirow{3}{*}{2} \\
\hline & sometimes & 46 & 22 & 34 & 21 & & & \\
\hline & no & 76 & 37 & 62 & 39 & & & \\
\hline \multirow{3}{*}{ Contact lenses } & everyday & 20 & 10 & 9 & 6 & \multirow{3}{*}{0.0301} & \multirow{3}{*}{$7.01^{\mathrm{a}}$} & \multirow{3}{*}{2} \\
\hline & sometimes & 36 & 17 & 16 & 10 & & & \\
\hline & no & 151 & 73 & 136 & 84 & & & \\
\hline \multicolumn{2}{|l|}{ Currently smoking } & 11 & 5 & 16 & 10 & 0.0915 & $2.85^{\mathrm{a}}$ & 1 \\
\hline \multicolumn{2}{|l|}{ Autoimmune diseases } & 15 & 7 & 11 & 7 & 0.8778 & $0.024^{\mathrm{a}}$ & 1 \\
\hline \multicolumn{2}{|c|}{ Medications which can cause DED } & 78 & 38 & 50 & 31 & 0.3219 & $2.2670^{\mathrm{a}}$ & 2 \\
\hline \multirow{3}{*}{$\begin{array}{l}\text { Time spent on screen } \\
\text { learning }\end{array}$} & increased & 190 & 92 & 155 & 96 & \multirow{3}{*}{0.0666} & \multirow{3}{*}{$5.42^{\mathrm{a}}$} & \multirow{3}{*}{2} \\
\hline & no changes & 16 & 8 & 4 & 2 & & & \\
\hline & decreased & 1 & 1 & 2 & 1 & & & \\
\hline \multirow{3}{*}{$\begin{array}{l}\text { Time spent on screen } \\
\text { entertainment }\end{array}$} & increased & 108 & 52 & 64 & 40 & \multirow{3}{*}{0.0021} & \multirow{3}{*}{$12.35^{a}$} & \multirow{3}{*}{2} \\
\hline & no changes & 77 & 37 & 59 & 37 & & & \\
\hline & decreased & 22 & 11 & 38 & 24 & & & \\
\hline \multicolumn{2}{|l|}{ Decreased vision acuity } & 84 & 41 & 64 & 40 & 0.4916 & $1.42^{\mathrm{a}}$ & 2 \\
\hline Breaks to look into the & stance & 74 & 36 & 77 & 48 & 0.0195 & $5.46^{\mathrm{a}}$ & 1 \\
\hline Eye drops & & 90 & 43 & 62 & 39 & 0.3369 & $0.92^{\mathrm{a}}$ & 1 \\
\hline No actions & & 37 & 18 & 36 & 22 & 0.2844 & $1.15^{\mathrm{a}}$ & 1 \\
\hline Ophthalmologist cons & & 19 & 9 & 9 & 6 & 0.1977 & $1.66^{\mathrm{a}}$ & 1 \\
\hline
\end{tabular}

Tests used: ${ }^{a} X^{2}$ test; ${ }^{b}$ Mann-Whitney U test; DED - dry eye disease; $d f$ - degrees of freedom. Bold indicates statistically significant results ( $p<0.05$ ).

Table 5. Normality test - the results of Shapiro-Wilk test

\begin{tabular}{|l|c|c|}
\multicolumn{1}{|c|}{ Tested variable } & W & p-value \\
\hline The number of new/intensified symptoms & 0.9269 & $<\mathbf{0 . 0 0 0 1}$ \\
\hline Age [years] & 0.6653 & $<\mathbf{0 . 0 0 0 1}$ \\
\hline Change in screen learning time [h] & 0.9441 & $<\mathbf{0 . 0 0 0 1}$ \\
\hline Change in screen entertainment time [h] & 0.9243 & $<\mathbf{0 . 0 0 0 1}$ \\
\hline
\end{tabular}

Bold indicates statistically significant results $(p<0.05)$

aimed at investigating new ways to protect the eyes, as well as for the treatment of symptoms caused by the exposure to prolonged screen time.

In our study, we did not examine anxiety or coping styles of students during COVID-19 pandemic in the context of DED. However, after analyzing current literature, we considered that aspect of the pandemic as significant, especially among Polish students. A high level of anxiety and stress was experienced by that group during the pandemic. Additionally, a negative impact of COVID-19 was observed more often in female rather than male students. Therefore, it was recommended to support students by providing them with psychological help during the time of the pandemic. ${ }^{20}$ Furthermore, older Polish population represented by participants of the University of the Third Age showed various levels of anxiety because of the pandemic, but none of the collected results in applied scales were elevated enough to identify high COVID-19-related anxiety. ${ }^{21}$

\section{Limitations}

The first limitation is related to the use of the original, not validated, self-report questionnaire. Secondly, the use of contact lenses has not been studied thoroughly. However, a small number of students declared themselves as lens users. Various stages of the pandemic and the regulations considering online and on-site learning may have had varying impacts on student populations. Therefore, the findings of the study should be interpreted in the specific context of November 2020, the time of lockdown in Poland, when online learning was a basis of education on the university level. 


\section{Conclusions}

Bearing our results in mind, we claim that eye complaints are extremely prevalent in the population of students. What is more, during the pandemic these symptoms intensified, which seemed to be caused by the extension of the screen time. The ocular complaints reported by students involved in e-learning should have prompted them to monitor their time spent in front of the electronic devices and take proper actions regarding the presenting symptoms. Finally, there is a need for better education on ocular hygiene to improve visual clarity and awareness of risk factors of DED.

\section{ORCID iDs}

Ada Sterczewska (ㄴ) https://orcid.org/0000-0002-0819-8512

Alicja Wojtyniak (1) https://orcid.org/0000-0001-8750-3011

Ewa Mrukwa-Kominek (ㅇ) https://orcid.org/0000-0002-1541-4666

\section{References}

1. Polish Ministry of Science and Higher Education. Ordinance No. 405 of March 11, 2020 on time constraint on some of the higher education and science entities in regard to COVID-19 prevention. https://dziennik ustaw.gov.pl/D2020000040501.pdf. Accessed January 17, 2021.

2. Titiyal JS, Falera RC, Kaur M, Sharma V, Sharma N. Prevalence and risk factors of dry eye disease in North India: Ocular surface disease indexbased cross-sectional hospital study. Indian J Ophthalmol. 2018; 66(2):207-211. doi:10.4103/ijo.IJO_698_17

3. Craig JP, Nichols KK, Akpek EK, et al. TFOS DEWS II definition and classification report. Ocul Surf. 2017;15(3):276-283. doi:10.1016/j.jtos. 2017.05.008

4. Ding J, Sullivan DA. Aging and dry eye disease. Exp Gerontol. 2012; 47(7):483-490. doi:10.1016/j.exger.2012.03.020

5. Courtin R, Pereira B, Naughton G, et al. Prevalence of dry eye disease in visual display terminal workers: A systematic review and meta-analysis. BMJ Open. 2016;6(1):e009675. doi:10.1136/bmjopen2015-009675

6. Yilmaz U, Gokler ME, Unsal A. Dry eye disease and depression-anxiety-stress: A hospital-based case control study in Turkey. PakJ Med Sci. 2015;31(3):626-631. doi:10.12669/pjms.313.7091

7. Inomata $\mathrm{T}$, Shiang $\mathrm{T}$, Iwagami $\mathrm{M}$, et al. Changes in distribution of dry eye disease by the new 2016 diagnostic criteria from the Asia Dry Eye Society. Sci Rep. 2018;8(1):1918. doi:10.1038/s41598-018-19775-3

8. Inomata T, Iwagami M, Hiratsuka $Y$, et al. Maximum blink interval is associated with tear film breakup time: A new simple, screening test for dry eye disease. Sci Rep. 2018;8(1):13443. doi:10.1038/s41598018-31814-7
9. Inomata T, Nakamura M, Iwagami M, et al. Risk factors for severe dry eye disease: Crowdsourced research using DryEyeRhythm. Ophthalmology. 2019;126(5):766-768. doi:10.1016/j.ophtha.2018.12.013

10. Santabárbara J, Lasheras I, Lipnicki DM, et al. Prevalence of anxiety in the COVID-19 pandemic: An updated meta-analysis of community-based studies. Prog Neuropsychopharmacol Biol Psychiatry. 2021;109:110207. doi:10.1016/j.pnpbp.2020.110207

11. Santabárbara J, Bueno-Notivol J, Lipnicki DM, et al. Prevalence of anxiety in health care professionals during the COVID-19 pandemic: A rapid systematic review (on published articles in MEDLINE) with meta-analysis. Prog Neuropsychopharmacol Biol Psychiatry. 2021;107: 110244. doi:10.1016/j.pnpbp.2021.110244

12. Lasheras I, Gracia-García P, Lipnicki DM, et al. Prevalence of anxiety in medical students during the COVID-19 pandemic: A rapid systematic review with meta-analysis. Int J Environ Res Public Health. 2021;17(18):6603. doi:10.3390/ijerph17186603

13. Li Y, Wang A, Wu Y, Han N, Huang H. Impact of the COVID-19 pandemic on the mental health of college students: A systematic review and meta-analysis. Front Psychol. 2021;12:669119. doi:10.3389/fpsyg. 2021.669119

14. Sharma D, Bhaskar S. Addressing the Covid-19 burden on medical education and training: The role of telemedicine and tele-education during and beyond the pandemic. Front Public Health. 2020;8:589669. doi:10.3389/fpubh.2020.589669

15. Giannaccare G, Vaccaro S, Mancini A, Scorcia V. Dry eye in the COVID19 era: How the measures for controlling pandemic might harm ocular surface. Graefes Arch Clin Exp Ophthalmol. 2020;258(11):2567-2568. doi:10.1007/s00417-020-04808-3

16. Cartes C, Segovia C, Salinas-Toro D, et al. Dry eye and visual display terminal-related symptoms among university students during the coronavirus disease pandemic. Ophthalmic Epidemiol. 2021;1-7. doi:10.1080/09286586.2021.1943457

17. Paulsen AJ, Cruickshanks KJ, Fischer ME, et al. Dry eye in the beaver dam offspring study: Prevalence, risk factors, and health-related quality of life. Am J Ophthalmol. 2014;157(4):799-806. doi:10.1016/j. ajo.2013.12.023

18. Garza-León M, Valencia-Garza M, Martínez-Leal B, et al. Prevalence of ocular surface disease symptoms and risk factors in group of university students in Monterrey, Mexico. J Ophthal Inflamm Infect. 2016;6(1):44. doi:10.1186/s12348-016-0114-z

19. Stapleton F, Alves M, Bunya VY, et al. TFOS DEWS II Epidemiology Report. Ocul Surf. 2017;15(3):334-365. doi:10.1016/j.jtos.2017.05.003

20. Rogowska AM, Kuśnierz C, Bokszczanin A. Examining anxiety, life satisfaction, general health, stress and coping styles during COVID-19 pandemic in Polish sample of university students. Psychol Res Behay Manag. 2020;13:797-811. doi:10.2147/PRBM.S266511

21. Cybulski M, Cwalina U, Sadowska D, Krajewska-Kułak E. The assessment of the severity of COVID-19-related anxiety symptoms in participants of the university of the third age in Poland: A cross-sectional study among internet survey respondents. J Clin Med. 2021;10(17): 3862. doi:10.3390/jcm10173862 